\title{
Energy Saving Awareness Among UTM Students
}

\author{
Mohd Jamsyeer Khan ${ }^{1 *}$, Abdul Salam bin A Haris ${ }^{1}$, Muhammad Nur Syollehin bin \\ Abdul Rahim ${ }^{1}$, Dr. Muhammad Aizi bin Mat Salim ${ }^{1}$, Dr. Muhammad Noor bin \\ Harun $^{1}$, Assoc. Prof. Dr. Mohd Haizal bin Jamaluddin ${ }^{1}$, Dr. Norhidayah binti Md. \\ Yunus ${ }^{1}$, Muhammad Nizam bin Lokman ${ }^{1}$, Abdul Rashid bin Zailan ${ }^{1}$, Nurshaidatul \\ Hidayah binti Mohd Nor ${ }^{1}$
}

${ }^{1}$ Kolej Rahman Putra, Universiti Teknologi Malaysia, 81310, Johor Bahru, Johor, Malaysia *Corresponding author. Email: jamsyeer@gmail.com

\begin{abstract}
Energy is an important element for economic competitiveness and employment and thus, a huge amount of energy is required in countries with faster economic growth. Higher institutions of learning such as universities spent a lot of money on energy bills due to the nature of their daily activities. This paper sought to determine the level of energy saving awareness among Universiti Teknologi Malaysia (UTM) students.

Therefore, a survey is conducted to determine the level of energy saving awareness in use of various electrical appliances and their preparedness to support efforts towards reducing energy wastage in institutions as well as in their home. The survey was carried out through the administration of questionnaires and it was distributed to the resident students of UTM. The results of the survey point to appreciable levels of energy saving awareness in the use of various consumer tools. The results show a high awareness level towards energy saving among UTM students, especially of the importance of energy saving. In addition, a significant number of UTM students were willing to support efforts towards reducing energy wastage, in terms of changing their habits, both on time and money to save more energy in the long run.
\end{abstract}

Keywords: Energy saving, awareness, university students, energy usage behaviour

\section{INTRODUCTION}

High level of electricity consumption in educational institutions with its attendant increase the energy bills which eventually raise the financial burden of managers in educational institutions [1]. High electricity use in educational institutions can be attributed, in part, to gross energy wastage due to inefficient electricity utilization, where it can be seen in significant wastage percentage of electrical energy used in educational [2]. To cite some examples, it is common to find lamps and fans switched on in classrooms, even air-conditioner still turned on when there is no occupant. The situations not only found in the lecture halls but also in labs and offices when there is no occupancy. As such, it is a must to develop and implement measures to reduce electricity consumption and hence to cut down the electricity bills of educational institutions to as lower as possible. As an evidence to encourage sustainable energy saving practice, The Malaysian Standard MS 1525:2007, Code of Practice on Energy Efficiency and use of Renewable Energy for NonResidential Buildings has been introduced. Students play a critical role in this instance and should bear their responsibilities in order to use energy in an effective and efficient way. In this case, electrical energy is wasted every day due to lack of awareness among students and in fact, energy awareness is the first step to achieve energy sustainability. Without energy awareness among the students, efforts to promote energy conservation can be difficult and lead to energy wastage.

\section{ENERGY CONSERVATION AND AWARENESS}

Energy conservation has been getting a lot of attention recently. There are also existing studies those analysed the Malaysian household's awareness on energy conservation. However, energy awareness amongst students and staff of Malaysian University is still abstract. The level of high energy awareness is still underdeveloped, so the researchers cannot provide a better energy conservation program at the university [3].

According to [4], energy awareness refers to the energy efficiency whereas Fragidis states the energy awareness alludes to consciousness of how much energy is used. Without the related knowledge, consumers or users do not conscious of when they use the electricity, how much they use it, and how much they cost at the right time which may influence their monthly electricity bills. Thus, it is very difficult for consumers to reduce the energy consumption if they do not have the energy awareness. [5] states that 
consumers who are more knowledgeable, are more interested in practicing energy-saving behaviour.

[6] carried out an energy awareness research among university students at Universiti Utara Malaysia (UUM) and his research comprised three decisive parts, which are knowledge, views and actions. The results of his research show that the UUM students generally have low level of awareness on energy saving. This has caused momentous burden on the university management as university need to pay for the cost of electricity bills. In his paper, Syed Hussein suggested that more integrated integration efforts can be made to increase the level of electric energy awareness among UUM students.

[7] has proposed the Context-Aware Framework for Collaborative Learning Applications (CAFCLA) framework to create a suggestion system for users to nurture energy savings in home. It combined the RealTime Localization System and Wireless Sensor Networks to create applications that operate under the Social Computing. This system able to identify the users' behavioural patterns and habits. The results show that this system helped the users to save about 17 percent of energy usage. The majority of the recommendations are associated to the utilization of heating (77\%), lighting (84\%) and turn off devices to prevent the stand-by consumption (92\%). This case study also show that it is possible to cultivate a good energy consumption habits for a long period of time.

\section{PROBLEM STATEMENTS}

1. What is the level of understanding on the importance of energy saving among UTM students?

2. What is the energy consumption behaviour being practiced by UTM students?

3. What is the type of energy wastage that is being applied by UTM students?

4. What is the level of awareness on energy wastage among the UTM students?

\section{METHODOLOGY}

The sample for the study was drawn from a population of 31,988 students of Universiti Teknologi Malaysia (UTM) in the academic year 2018/2019. They are varying from 7 faculties and 10 residential colleges in UTM. The sample of 100 students is taken in this research to study the relationship between awareness of energy saving and behaviour of students in UTM. Figure 1 shows the survey process in order to fulfil this paper's objectives.

\subsection{Research Instrument}

The main instrument employed in this research for data collection is by using questionnaire that was created using Google Form. The questionnaire includes the demographic information, the level of awareness on energy saving and energy saving behaviour of students which used 5-point rating scale. The literature review of previous studies is done beforehand so that the questions are reliable and be able to obtain the relationship between behaviour and awareness.

\subsection{Data Collection}

The collection of data is conducted through online method. The target of respondents is 100 , however, in this case, 106 respondents have completed the survey questionnaires. From the 106 surveys collected, the subsequent analysis categorized each questionnaire by gender, faculties, residential colleges and current year of study, which are shown in Figure 2 and 3.

\subsection{Data Analysis}

The results were analysed by using descriptive statistics including mean and standard deviation to find the relationship between awareness and behaviour of students in UTM. Figure 2 and 3 shows the background of respondents according to gender, year of study, college and faculty.

\section{OBJECTIVES}

1. To assess the energy saving awareness among the UTM students.

2. To assess the behaviour on usage of energy among the UTM students.

3. To determine the relationship between energy awareness and energy usage behaviour among the UTM students. 


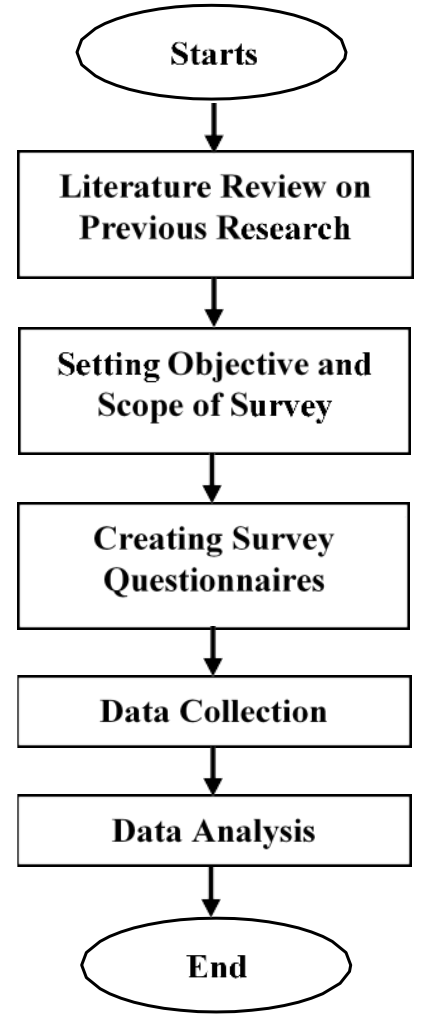

Figure 1 Flow Chart of the survey process

\section{RESULT AND ANALYSIS}

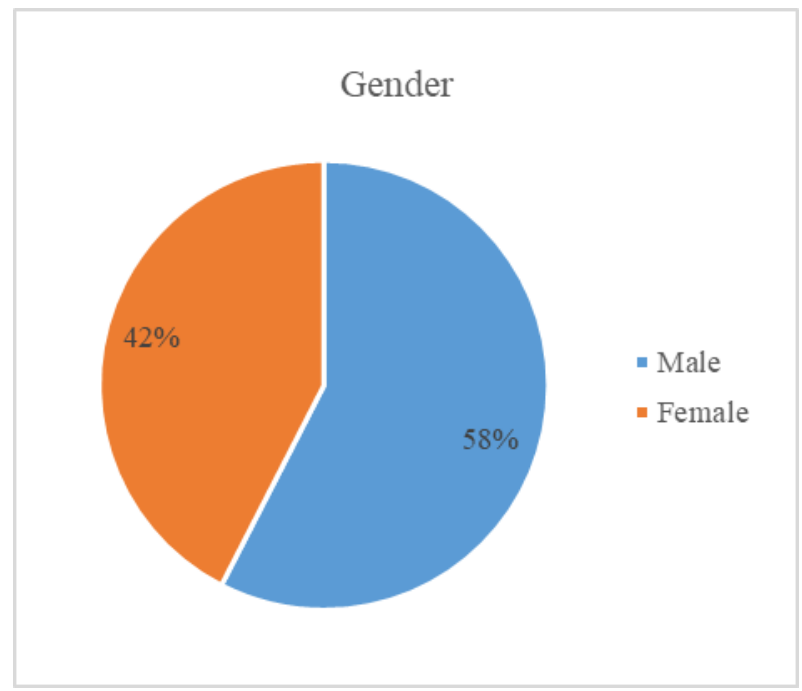

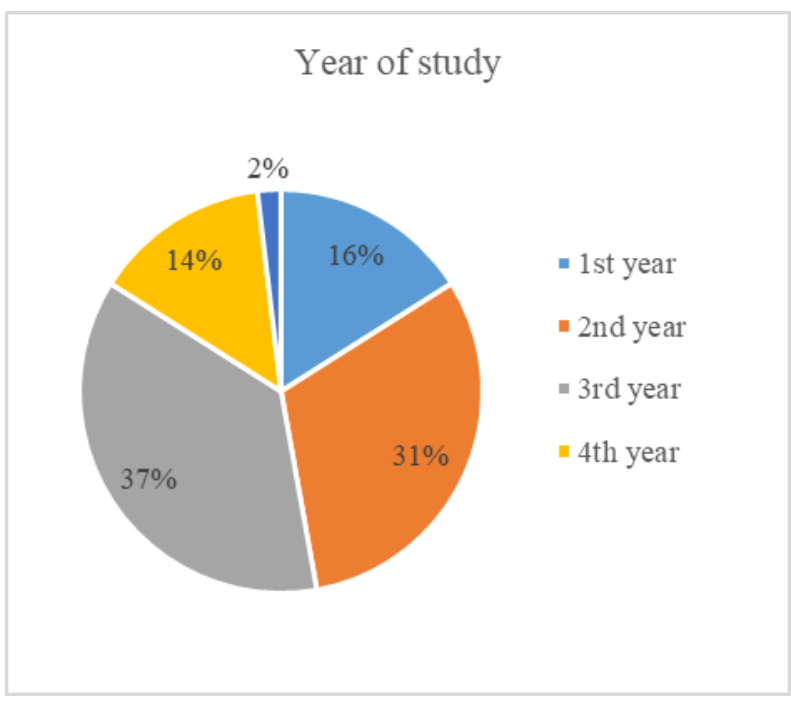

Figure 2 Respondent background for gender and year of study

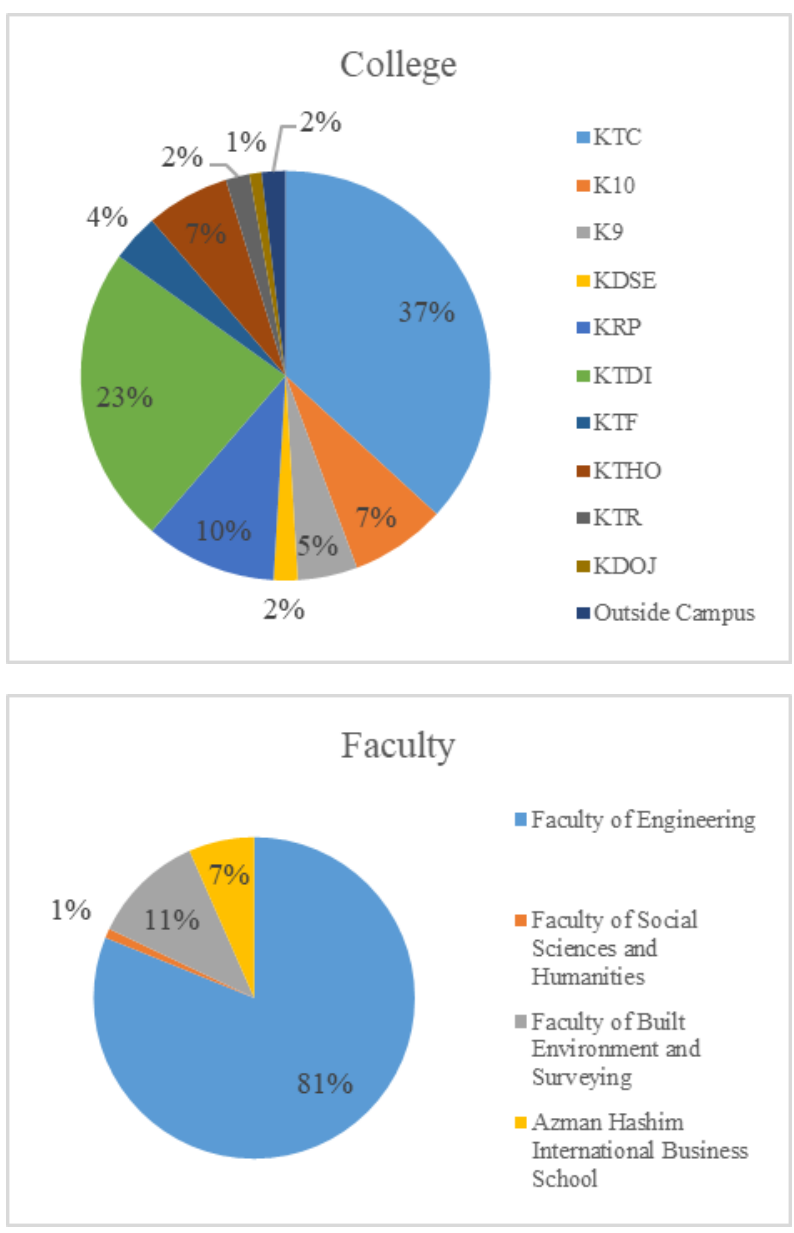

Figure 3 Respondent background for college and faculty 
Table 1 Result of Awareness Assessment

\begin{tabular}{|c|c|c|c|c|c|c|c|}
\hline No. & Question & 5 & 4 & 3 & 2 & 1 & Mean \\
\hline 1 & Energy saving is important. & 76 & 21 & 8 & 1 & 0 & 4.623 \\
\hline 2 & $\begin{array}{l}\text { Energy we use comes from electrical energy } \\
\text { which is generated using precious natural } \\
\text { resources. }\end{array}$ & 61 & 35 & 10 & 0 & 0 & 4.481 \\
\hline 3 & $\begin{array}{l}\text { By energy saving, you are saving precious natural } \\
\text { resources. }\end{array}$ & 57 & 40 & 7 & 1 & 1 & 4.425 \\
\hline 4 & $\begin{array}{l}\text { Some of our simple habits can contribute to global } \\
\text { effort in energy saving }\end{array}$ & 60 & 37 & 8 & 0 & 1 & 4.462 \\
\hline 5 & $\begin{array}{l}\text { Some equipment consumes a lot more energy than } \\
\text { the others based on the power rating. }\end{array}$ & 47 & 41 & 16 & 2 & 0 & 4.255 \\
\hline 6 & The concept of energy efficiency. & 53 & 30 & 19 & 1 & 3 & 4.217 \\
\hline 7 & $\begin{array}{l}\text { ENERGY STAR label on electrical appliances like } \\
\text { light bulb, fan, air conditioner, refrigerator, } \\
\text { television. }\end{array}$ & 36 & 43 & 18 & 7 & 2 & 3.981 \\
\hline 8 & $\begin{array}{l}\text { Appliance with Energy Star label will consume less } \\
\text { energy during use compared to standard non- } \\
\text { energy efficient models. }\end{array}$ & 48 & 29 & 20 & 7 & 2 & 4.075 \\
\hline 9 & Your electrical appliances are energy efficient. & 26 & 42 & 27 & 7 & 4 & 3.745 \\
\hline 10 & Ways of saving energy. & 40 & 43 & 20 & 3 & 0 & 4.132 \\
\hline
\end{tabular}

Table 2 Mean Range Interpretation for Likert-Scale

\begin{tabular}{|c|c|}
\hline $\begin{array}{c}\text { Mean } \\
\text { Range }\end{array}$ & Descriptive Interpretation \\
\hline $4.51-5.00$ & Very high awareness level \\
\hline $3.51-4.50$ & High awareness level \\
\hline $2.51-3.50$ & Moderate awareness level \\
\hline $1.51-2.50$ & Low awareness level \\
\hline $1.00-1.50$ & Very low awareness level \\
\hline
\end{tabular}

The first part of the analysis is to assess the awareness level of the respondents toward energy saving. Respondents are required to give their response to 10 Likert-scale based questions as shown in Table 1. The response to the question is valued from 1 to 5 , with 5 being the highest level of awareness and vice versa. Later, the mean values for each items and the overall mean for the 10 items are computed. Eventually, the level of awareness to each statement and the overall level of awareness toward energy saving are interpreted based on the mean range they fall upon as shown in Table 2.

Generally, the total average mean of every item records a value of 4.24, indicating a high awareness level of UTM students toward energy saving. This can be attributed to the fact that most respondents are aware of the importance of energy saving, with a mean of 4.623 , which is situated in the mean range of very high awareness level. Besides, the respondents are generally well-informed on the fact that electrical energy is generated using precious natural resources, and the fact that energy saving means saving natural resources, as well as the valuable contribution of simple habitual changes for the sake of energy saving. This awareness contributes greatly to the high awareness level toward energy saving as a whole, with recorded means of $4.481,4.425$ and 4.462 respectively. This is closely followed by awareness toward different energy consumption rate of different equipment $(\mu=4.255)$, awareness toward concept of energy efficiency registering $(\mu=4.217)$, and awareness toward ways of saving energy $(\mu=4.132)$. The lowest mean recorded is 3.745 for being aware that electrical appliances are energy efficient.

The computed standard deviation for the means of the 10 items is 0.253 , which suggests that the mean of each item deviates considerably from the total average mean of 4.24.

$$
\frac{0.253}{4.24} \times 100 \%=5.967 \%
$$

In other words, the awareness of UTM students toward each statement in Table 1 is not consistent, where some students might be well aware of a specific fact regarding energy saving but are lacking certain knowledge on the others. 
Table 3 Result of Energy Usage Behaviour Assessment

\begin{tabular}{|c|c|c|c|c|c|c|}
\hline No. & Question & Yes & Yes & No & No & Mean \\
\hline 1 & Participate in earth hour campaign to save energy. & 56 & $52.83 \%$ & 50 & $47.17 \%$ & 0.5283 \\
\hline 2 & $\begin{array}{l}\text { Practice energy saving techniques at hostel or } \\
\text { home. }\end{array}$ & 82 & $77.36 \%$ & 24 & $22.64 \%$ & 0.7736 \\
\hline 3 & Switch off light during day time. & 71 & $66.98 \%$ & 35 & $33.02 \%$ & 0.6698 \\
\hline 4 & Do not leave phone charging overnight. & 54 & $50.94 \%$ & 52 & $49.06 \%$ & 0.5094 \\
\hline 5 & $\begin{array}{l}\text { Turn the electrical appliances to standby mode } \\
\text { after used. }\end{array}$ & 42 & $39.62 \%$ & 64 & $60.38 \%$ & 0.3962 \\
\hline 6 & Turn off the electrical appliances after used. & 96 & $90.57 \%$ & 10 & $9.43 \%$ & 0.9057 \\
\hline 7 & $\begin{array}{l}\text { Hang drying my clothes instead of using dryer } \\
\text { machine. }\end{array}$ & 82 & $77.36 \%$ & 24 & $22.64 \%$ & 0.7736 \\
\hline 8 & $\begin{array}{l}\text { Wash my clothes manually instead of using } \\
\text { washing machine. }\end{array}$ & 41 & $38.68 \%$ & 65 & $61.32 \%$ & 0.3868 \\
\hline 9 & $\begin{array}{l}\text { Ensure the air conditioner and light are } \\
\text { switched off before I leave the classroom. }\end{array}$ & 86 & $81.13 \%$ & 20 & $18.87 \%$ & 0.8113 \\
\hline 10 & Switch off laptop charger when its battery is full. & 55 & $51.89 \%$ & 51 & $48.11 \%$ & 0.5189 \\
\hline 11 & $\begin{array}{l}\text { Switch off fan and light of your room when you } \\
\text { go out. }\end{array}$ & 80 & $75.47 \%$ & 26 & $21.70 \%$ & 0.7547 \\
\hline
\end{tabular}

Total mean $=0.6389$ Standard deviation $=0.1699$

Based on the questions regarding the general behaviour of respondents on their general usage behaviour, it can be seen with a total general mean of 0.6389 out of 1.0 that the actual action taken in conserving energy usage is not very commendable. Converting 0.6389 to match the scale provided by Table 2 would be 3.1945 which sits at the moderate behavioural level. Among the factors that pull down the general mean value are not switching off laptop charger when the battery is full at $48.11 \%$, overnight charging phone at $49.06 \%$, not turning the electrical appliances to standby mode after use at $60.38 \%$ and using washing machines instead of manually at $61.32 \%$. These are all simple actions that can be done in a short period of time. However, the good news is that the respondents make a habit of turning off electrical appliance after use at $90.57 \%$ and they ensure that the air conditioner and light are both switched off before leaving the classroom at $81.13 \%$. The baffling part is that both the activities that score extremely low marks and high marks have no major distinction. They do not differ in time taken to be done nor do they need extra effort in doing so to help conserve energy.

The standard deviation of the total general mean is 0.1699 .

$$
\frac{0.1699}{0.6389} \times 100 \%=26.59 \%
$$

This shows a strong severity of the deviation in the behaviour of the respondents. The respondents do not show a distinct characteristic that explains why they choose not to take a similar action that could cut down energy usage. One fine example is that the respondents are willing to turn off the appliance after use $(90.57 \%)$ but the awareness to turn the electrical appliances to standby mode after use is relatively low (39.62\%). 
Table 4 Result of Assessment of Willingness of Respondent to Take Initiative on Energy Saving

\begin{tabular}{|c|l|c|c|c|c|}
\hline No. & \multicolumn{1}{|c|}{ Question } & Yes & Yes & No & No \\
\hline 1 & Change habits for energy saving. & 101 & $95.28 \%$ & 5 & $4.72 \%$ \\
\hline 2 & Spend time learning about energy saving. & 93 & $87.74 \%$ & 13 & $12.26 \%$ \\
\hline 3 & $\begin{array}{l}\text { Spend more money on energy efficient appliances which } \\
\text { usually have higher purchase prices. }\end{array}$ & 77 & $72.64 \%$ & 26 & $27.36 \%$ \\
\hline
\end{tabular}

With a high awareness level toward energy saving and a moderate behavioural level in terms of actually making efforts to save energy, we can see the correlation between the energy saving awareness and energy saving behaviour among UTM students. It can be said that the behaviour to save energy trails behind the knowledge and awareness that the respondents possess. The higher standard deviation value at $26.59 \%$ for energy usage behaviour compared to $5.967 \%$ of energy saving awareness tells that the respondents are selective in choosing what to do and what not to do in conserving energy consumption despite having plenty knowledge and understanding of the importance in energy conservation. Table 4 shows that the respondents are generally willing to take action on energy saving in terms of changing their habit or spending time and money to save more energy in the long run.

\section{CONCLUSION}

To sum it up, the awareness level and energy usage behaviour are assessed in this paper, and the correlation between them are discussed. Overall, it is indicated that UTM students have high awareness level toward energy saving, however somehow, the same respondents have only pass moderate behavioural level towards general usage of electricity. Despite that the relationship between awareness level and behaviour in energy saving is not directly linearly related, the respondents show great enthusiasm and willingness to initiate energy saving practices. Perhaps with this, UTM students are more aware on conserving electricity both in UTM and homes, starting by changing their lifestyle and habits as part of energy saving initiatives.

\section{ACKNOWLEDGMENT}

The authors would like to express gratitude to Kolej Rahman Putra, Universiti Teknologi Malaysia and Wireless Communication Centre, Universiti Teknologi Malaysia for sponsorship on this research.

\section{REFERENCES}

[1] E. Twumasi, E.A. Frimpong MIEEE, F. Kemausuor, D.O. Appiah, P.Y. Okyere, Energy Efficiency Awareness and Preparedness Among Students, in Journal of IEEE PES-IAS Power Africa, June 2017.

[2] E.A. Frimpong, P.Y. Okyere, E.K. Anto, Assessment of Energy Wastage in Street Lighting, in Journal of Multidisciplinary Engineering Science Studies, vol. 2, no. 7, pp. 639-641, 2016.

[3] K.A. Rahman, A.B. Leman, M.Z.M Yusof, Consumer Awareness in Energy Efficiency for Residential Houses in Peninsular Malaysia, in MATEC Web of Conferences, p. 78, 2016.

[4] Cordis, Energy aware means energy efficient, in: Phy.org, 20 September 2013. [Online]. Available: https://phys.org/news/2013-09-energy-awareefficient.html. [Accessed 8 May 2019].

[5] T. N. B., TNB, 2014.

[6] T.P.R. Syed Hussain, H. Ismail, M.K. Md Noh, PERKEM Proceedings 2, 2013.

[7] O. Garcia, J. Prieto, R.S. Alonso, J.M. Corchado, A Framework to Improve Energy Efficient Behaviour at Home through Activity and Context Monitoring [Online]. Available: https://www.ncbi.nlm.nih.gov/pmc/articles/PMC55798 $31 \%$. 